E3S Web of Conferences 1, 24006 (2013)

DOI: $10.1051 / \mathrm{e} 3$ sconf/20130124006

C Owned by the authors, published by EDP Sciences, 2013

\title{
Arsenic in drinking water in Northern region of Serbia
}

\author{
B. Stanisavljev ${ }^{1}$, Z. Bulat ${ }^{2}$, A. Buha ${ }^{3}$ and $\underline{\text { V. Matović }}{ }^{4}$ \\ ${ }^{1}$ Institute of Public Health Zrenjanin, Zrenjanin, Serbia, biljast1@gmail.com \\ ${ }^{2}$ Department of Toxicology „Akademik Danilo Soldatovic““, University of Belgrade-Faculty of Pharmacy, Belgrade, Serbia, \\ zorica.bulat@pharmacy.bg.ac.rs \\ ${ }^{3}$ Department of Toxicology „Akademik Danilo Soldatović“, University of Belgrade-Faculty of Pharmacy, Belgrade, Serbia, \\ aleksandra@pharmacy.bg.ac.rs \\ ${ }^{4}$ Department of Toxicology „Akademik Danilo Soldatovic““, University of Belgrade-Faculty of Pharmacy, Belgrade, Serbia, \\ vevodi@pharmacy.bg.ac.rs
}

\begin{abstract}
In this study we present the results of arsenic concentration in water samples from public water supply system of city Zrenjanin and three Northern municipalities Elemiš, Taraš and Melenci taken every month during 2002, 2007 and 2011. Total arsenic content was determined using AAS technique with hydride generation system. Determined levels of arsenic in all investigated samples were more than 10 times higher than the maximum permissible limit recommended by WHO $(10 \mu \mathrm{g} / \mathrm{L})$ and even reached levels higher than $300 \mu \mathrm{g} / \mathrm{L}$. During 2011 drinking water from 44 pump wells in Zrenjanin was also analyzed showing that more than $50 \%$ of pump wells contain more than $10 \mu \mathrm{g} \mathrm{As} / \mathrm{L}$. These findings can be explained by geological characteristics of Northern region of Serbia belonging to Pannonian Basin which has aquifers that contain high concentration of naturally occurring arsenic. Results suggest that arsenic levels in this Serbian region are even higher than in other countries in the Pannonian Basin. Having in mind profound deleterious effects of arsenic on human health, different social, economical and technological measures are required in order to reduce arsenic concentration to acceptable limits.
\end{abstract}

Key words: arsenic, drinking water, Northern Serbia

\section{Introduction}

Arsenic (As) is a toxic element that is ubiquitously present in the environment. It can enter environment as a result of natural processes such as weathering and volcanic eruptions as well as anthropogenic activities such as mining, the use of pesticides, burning of coals with high concentration of arsenic etc. Inorganic and organic forms of arsenic both occur in the environment with inorganic forms being more abundant. Inorganic form is present mainly in nonionic trivalent $(\mathrm{As}(\mathrm{III}))$ and ionic pentavalent $(\mathrm{As}(\mathrm{V}))$ forms in different proportions depending on the environment conditions (Sharma and Sohn, 2009).

This toxic metalloid has been classified as a human carcinogen affecting skin and lungs (IARC, 2004). Chronic exposure to arsenic can have toxic impact on human health, causing skin disorders, cardiovascular diseases, neurological complications, reproductive disorders, respiratory effects etc. (Rahman et al., 2009).

Human exposure to arsenic primarily occurs through drinking water (WHO, 2001). The range of As concentration found in natural waters is large, ranging from less than 0.5 to more than $5000 \mu \mathrm{g} / \mathrm{L}$. Typical concentrations in freshwater are less than $10 \mu \mathrm{g} / \mathrm{L}$ (WHO guideline for arsenic in drinking water) and frequently less than $1 \mu \mathrm{g} / \mathrm{L}$. Even though high arsenic content is not typical for groundwater, in recent years the occurrence of high arsenic content in groundwater has been reported from many parts of the world, particularly from Southeast Asia and it is estimated that this number will grow in future since determination of arsenic content has not been the part of routine analysis of water quality. Hence, arsenic poisoning has been recognized as a serious health hazard of global concern affecting more than 100 million people worldwide 


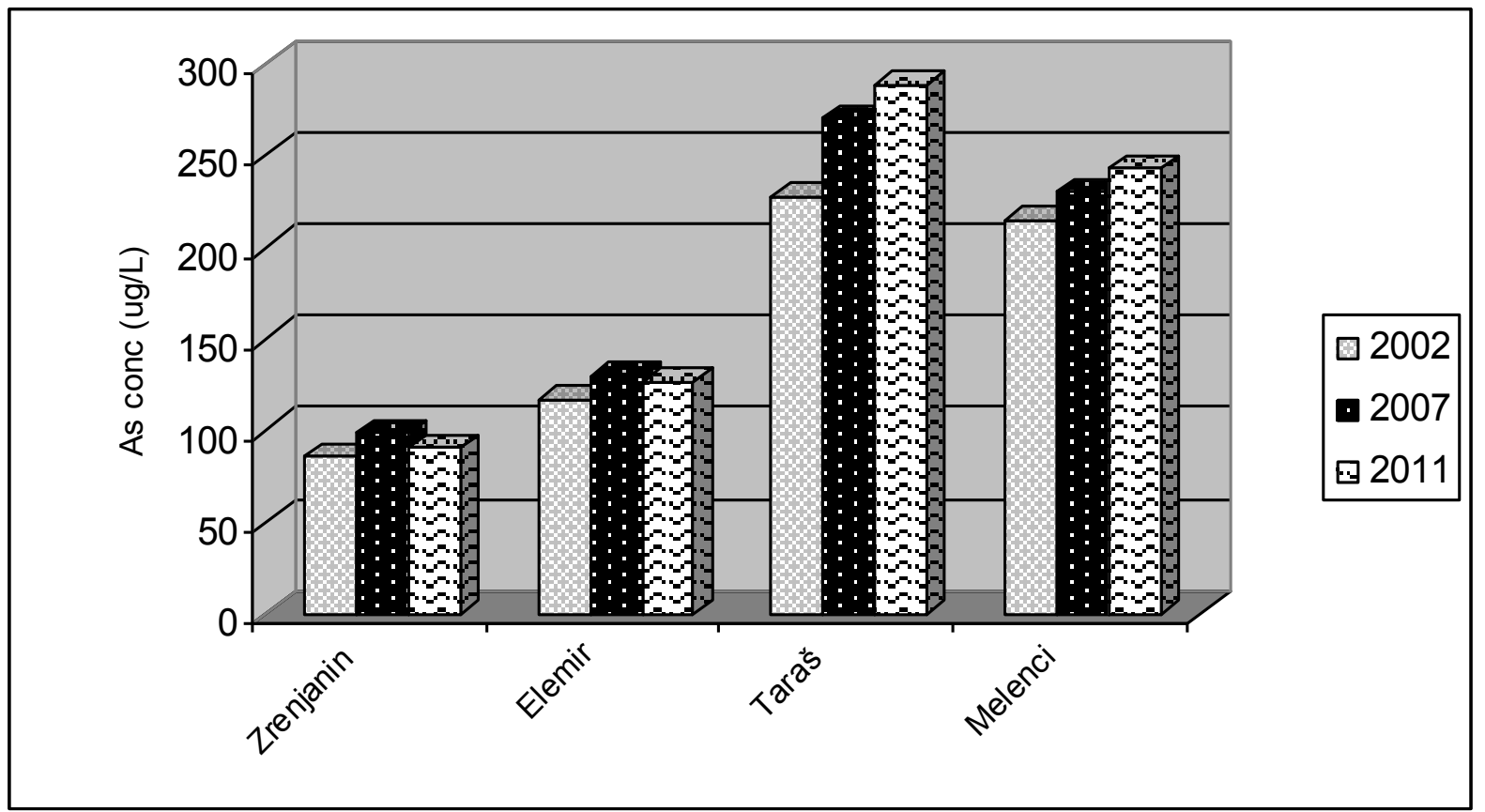

Fig. 1 Levels of arsenic in water samples collected from Zrenjanin and 3 Northern municipalities during 2002, 2007 and 2011.

(NRC, 2001).

Vojvodina, Northern region of Serbia belonging to the Pannonian Basin has aquifers that contain high concentration of naturally occurring arsenic (Varsaniji and Kovacs, 2006). Arsenic has been well known water pollutant in Vojvodina for many decades and since it does not change water color, odor or taste population that lives in this part of Serbia uses this contaminated water for drinking and other purposes, thus ingesting large amounts of arsenic. Zrenjanin is the city situated in Eastern part of Vojvodina. Groundwater that is used for water supplying of Zrenjanin has very complex physical and chemical composition.

\section{Materials and Methods}

Total arsenic concentration were measured in water samples from public water supply system of city of Zrenjanin and three surrounding settlements Elemiš, Tarašand Melenci every month during 2002, 2007 and 2011. Samples of drinking water from 44 pump wells in Zrenjanin were also analyzed during 2011.

All water samples were collected in polyethylene bottles and preserved with hydrochloric acid. Due to organic substances present in samples, digestion was performed with mixture of sulfuric acid and hydrogen peroxide. The reduction of As (V) to As (III) was carried out by addition of hydrochloric acid and potassium iodideascorbic acid mixture. Reagents of analytical grade and higher quality were used. Total arsenic content was determined using AAS technique (Perkin-Elmer atomic absorption spectrometer equipped with MHS-10 hydride generation system, Perkin-Elmer Corp., Norwalk, CT, USA). The radiation source was a hollow cathode lamp of arsenic (Perkin-Elmer). With this method a limit of detection of $0.7 \mu \mathrm{g} / \mathrm{L}$ and limit of quantification of $2.2 \mu \mathrm{g} / \mathrm{L}$ were obtained and recovery values were ranging from 87.5 to $106.25 \%$ (mean value $95.14 \%$ ). All results are present as mean values.

\section{Results and Discussion}

Arsenic levels in water samples from public water supply system in Zrenjanin, Elemiš, Taraš and Melenci are presented in Figure 1.

Monthly arsenic monitoring showed that arsenic levels varied to a lesser extent depending on season and that increased values were held throughout whole year. The lowest levels of As were obtained for Zrenjanin with mean values of 86, 98.5 and $91 \mu \mathrm{g} / \mathrm{L}$ for 2002, 2007 and 2011, respectively. The highest concentrations were reported in the municipality of Taraš in all three investigated years with highest value $(344 \mu \mathrm{g} / \mathrm{L})$ obtained in November 2002. Similar arsenic levels obtained in years 2002, 2007 and 2011, suggest that arsenic levels have been constantly elevated in this part of Serbia for almost a decade. It should be emphasized that drinking water in Zrenjanin and its Northern municipalities originates from standing water from deep aquifers $(80-135 \mathrm{~m})$. This water is chlorinated 
and then released to public water supply system. However, this groundwater was formed 20 to 30000 years ago and due to long term interaction with sediments various minerals and organic ingredients were washed away. Consequently, quality of water from deep aquifers of this part of Serbia has never been able to fulfill many criteria regarding water quality guidelines.

Due to the lack of regular water supply in the city of Zrenjanin, citizens are forced to drink water from pump wells. These wells pump water from aquifers located at a shallow depth (around $25 \mathrm{~m}$ ). The highest As content in drinking water of pump wells in city of Zrenjanin was 40 $\mu \mathrm{g} / \mathrm{L}$, and levels of As in water of 24 out of 44 investigated pump wells have exceeded both Serbian and WHO drinking water standards regarding As levels $10 \mu \mathrm{g} / \mathrm{L}$ (Book of Regulations on the Hygienic Correctness of Drinking Water, 1998; WHO, 2001).

Situation in this part of Serbia is rather similar to the one in Bangladesh where more than $50 \%$ of groundwater wells contain over $10 \mu \mathrm{g} / \mathrm{L}$ of arsenic (Yu et al., 2003), higher than in Spain where arsenic levels range from 1 to $118 \mu \mathrm{g} / \mathrm{L}$ (Medrano et al., 2010) and than in Slovakia where only $8 \%$ of samples exceed the Standards (Linberg et al., 2006). Results obtained in this study are in accordance with the results of Jovanovic et al. (2011) who showed that maximal values of arsenic from ten municipalities in Vojvodina reached $349 \mu \mathrm{g} / \mathrm{L}$ (median values from 2 to 250 $\mu \mathrm{g} / \mathrm{L})$.

\section{Conclusion}

Arsenic is a serious threat to human health and it represents a serious matter of public health concern. These results suggest that different social, economical and technological actions are necessary in order to reduce arsenic concentration to acceptable limits. Further investigations on arsenic exposure and risk assessment in population of this region in Serbia are also required.

\section{Acknowledgments}

The authors thank the financial support providing from Ministry of education and science, Republic of Serbia (Project III 46009).

\section{References}

Book of Regulations on the Hygienic Correctness of Drinking Water 98/42, 1998, Službeni list SRJ 42/98, Belgrade, Serbia

IARC (International Agency for Research on Cancer). 2004. Monographs, Vol. 84. IARC monographs on arsenic in drinking water; IARC, Lyons, France.

Jovanovic D, Jakovljević B, Rašić-Milutinović Z, Paunović K, Peković G, Knezević T. Arsenic occurrence in drinking water supply systems in ten municipalities in vojvodina region, serbia. Environ Res 2011;111:315318.

Lindberg A, Goessler W, Gurzau E, Koppova K, Rudnai P, Kumar R, et al. Arsenic exposure in Hungary, Romania and Slovakia. J EnvironMonitor 2006;8:203208.

Medrano MJ, Boix R, Pastor-Barriuso R, Palau M, Damián $\mathrm{J}$, Ramis R, et al. Arsenic in public water supplies and cardiovascular mortality in Spain. Environ Res 2010;110:448-454.

NRC Arsenic in Drinking Water: Update National Academy Press, Washington, D.C. 2001.

Rahman MM, Ng JC, Naidu R. Chronic exposure of arsenic via drinking water and its adverse health impacts on humans, Environ Geochem Health 2009; 31, suppl. $1: 189-200$

Sharma VK, Sohn M. Aquatic arsenic: Toxicity, speciation, transformations, and remediation. Environ Int 2009; 35:743-759.

Varsányi I, Kovács, LO. Arsenic, iron and organic matter in sediments and groundwater in the Pannonian Basin, Hungary. Appl Geochem 2006; 21:949-963.

WHO (World Health Organization). IPCS environmental health criteria 224 Arsenic and arsenic compounds. Geneva: International Programm on Chemical Safety, World Health Organization. 2001.

$\mathrm{Yu}$ WH, Harvey CM, Harvey CF. Arsenic in groundwater in bangladesh: A geostatistical and epidemiological framework for evaluating health effects and potential remedies. Water Resour Res 2003;39:WES11WES117. 